\title{
Research on the Application of Cloud Computing Auxiliary Teaching in Chinese Higher Vocational Course Teaching
}

\author{
Li Yongliang \\ Shandong Transport Vocational College, Weifang City, Shandong Province ,261206
}

\begin{abstract}
With the development of science and technology in China, it enriches the teaching methods of higher vocational colleges and creates a good learning environment for students. In order to send more comprehensive talents to the country in order to further promote the pace of national development, college education has been concerned by people from all walks of life. In order to improve the teaching quality of colleges and universities, cloud computing vocational education information technology has been widely used in the field of higher vocational education.
\end{abstract}

Keywords: cloud computing; auxiliary teaching; college teaching; applied analysis

In recent years, through the in-depth research and exploration of cloud computing by experts in the field of education, cloud computing vocational education information technology has not only been limited to the level of network computing, but also has the functions of load balancing, network storage and redundant backup. For the current higher vocational curriculum teaching provides a lot of convenience. Cloud computing technology is different from the traditional service mode in the past. It can provide a good management and supervision platform for teachers, parents and students, so that students, teachers and parents can share resources, communicate without hindrance and accomplish different tasks of authority on the platform.

\section{Analysis on the Present Situation of Teaching in Higher Vocational Colleges}

(1) The teaching idea is too old and neglects the student's main position 
At present, the teaching mode of college curriculum is still based on traditional teaching, with teachers as the leading person to impart knowledge, and students take notes carefully to deal with the subject examination. Therefore, in the course of teaching, due to the limitation of class hours, the teacher fails to provide students with sufficient thinking space and atmosphere for discussion, so that students' ideas and opinions can not be effectively brought into play, and to find problems completely according to the teacher's ideas. In the long run, students will gradually lose interest in learning, which is not conducive to the development of students' thinking and innovative ability, and is even more conducive to the improvement of students' consciousness of independent thinking ]

(2) Ignoring the importance of computer courses

Computer has become an indispensable part of people's daily life and provides great convenience for people's life. Therefore, computer technology has been widely used in various fields. At present, many educators in colleges and universities have a very shallow understanding of the importance of computer courses, and pay more attention to their independence in the process of teaching. Therefore, teachers ignore the integration and expansion of other majors in the development of teaching courses. According to the traditional teaching mode, other professional knowledge and computer teaching content are disjointed and The track of educational goals. It is this kind of examination-oriented education concept that completely ignores the learning level between students, which leads to the great difference of students' learning level in the same course. Some students do not have enough knowledge and are in a state of understanding, which seriously affects the quality of classroom teaching.

(3) Low utilization of teaching resources

As a big country, China has a vast territory, but due to the difference of geographical location and environment, there is a significant difference in the development of economic benefits in various regions, and it also seriously affects the balance of educational level. The middle and east part belongs to the coastal area, which is an important trade export area in China. It has convenient transportation and rapid economic development. Compared with the western region, the economic development level is far ahead. Therefore, the educational level in the western region is relatively backward, the sharing of teaching resources can not be realized, and the effective utilization of teaching resources has caused extreme waste. Secondly, with the popularization of quality education, most colleges and universities have Emphasis is placed on the construction of the resource sharing platform on campus, but the students' recognition of this technology is not high and can not be used reasonably, which leads to the idle resource sharing platform most of the time, and no one asks for ${ }^{[2]}$.

\section{Advantages of Cloud Computing Technology in Schools}


(1) Cost savings for hardware

SAAS software technology in cloud computing can transmit effective programs for users. This technology can greatly save the cost of purchasing servers and software, and provide convenient conditions for users. In order to improve the teaching quality, higher vocational colleges can not do without the renewal of teaching software. However, the cost of purchasing software is huge, which seriously affects the balance of school cost and expenditure. Applying cloud computing technology to colleges and universities creates a cloud through cloud providers The database can store all the teaching data, memory and computer ability into the cloud database, construct effective teaching resources, and update the teaching resources in time according to the teaching needs of different stages, and then provide new and rich teaching resources for teaching through the form of network, thus saving the huge cost of purchasing teaching software every semester. At the same time, cloud computing technology does not require high network equipment, to a certain extent, greatly meet the needs of users, very suitable for the teaching environment in colleges and universities, so that colleges and universities no longer need to update teaching equipment. It saves a lot of money for the purchase and maintenance of teaching equipment.

(2) Cloud computing provides a resource-sharing platform on campus

With the increasing consummate of Internet technology, it is helpful for colleges and universities to select service suppliers that match the teaching standards, and to make use of the rich teaching resources provided by service suppliers. Carry out teaching work smoothly. Because the service functions provided by Internet service providers are applicable to various units and fields, higher vocational schools can select Internet service providers that meet the school's price and function according to their own development needs and cost expenditure standards. In order to achieve a balanced development of the two. When cloud computing technology has not been popularized, higher vocational colleges can only use local teaching resources, so that The acquisition of teaching resources is very limited. However, compared with the past technology, cloud computing technology can upload local resources to the cloud database, reintegrate all teaching resources to form Internet cloud services. Then the cloud service provides effective resources for college teaching. At the same time, the Internet cloud service can effectively integrate the teaching resources of others with their own teaching resources, realize the sharing of resources, and make full use of the teaching resources. It also effectively solves the problem of high cost of updating teaching resources Environment, for the rapid development of the school to create a good foundation. In addition, cloud computing technology platform can also provide advanced teaching ideas for higher vocational colleges, effectively combine with innovative teaching ideas, and create a new concept training platform for students. Further strengthen the comprehensive quality of students and professional literacy. 
(3) The application of cloud technology is helpful to the education informationization of higher vocational schools

The maturity of network technology promotes the reform of education mode and makes the teaching mode more inclined to network information. With the increasing of teaching resources, the traditional teaching methods are no longer in line with the current students' psychological demands. In order to improve the teaching efficiency and fully arouse the enthusiasm of students, teachers should make indepth research and excavation on teaching methods, so as to innovate various teaching methods and make the teaching mode more diversified. Therefore, teachers can make full use of cloud computing technology, enrich teaching means, teaching In the process of learning, we can create a teaching platform suitable for ourselves with the help of cloud computing platform, create a diversified learning environment for students, and make students more actively and enthusiastically invest in learning. It not only saves the cost of hardware and software, but also saves the construction time cost and paves the way for the healthy development of university education informatization.

\section{Analysis on the Application of Cloud Computing Auxiliary Teaching in Higher Vocational Course Teaching}

(1) Constructing Interactive Teaching Environment

The application of cloud computing technology in the teaching process can improve and adjust the teaching interaction mode. In the past teaching mode, teacher-student interaction or student-student interaction occupy the main position in teaching interaction. However, there is a great drawback of this interaction, that is, ignoring the difference of students' learning level. The application of cloud computing technology, the main body of interaction successfully transferred to the network, to achieve human-computer interaction. In the designated teaching environment, students can combine the teaching contents and characteristics of the subject with their own learning needs through network services, formulate their own learning methods, according to the rich teaching resources provided on the network, Screen out the materials you need for learning and supplementary ${ }^{[4]}$. In the whole teaching process, the teaching mode is mainly man-machine dialogue, that is, students and the network, cloud computing technology can receive students' learning needs no matter when, where or at any terminal.

Therefore, the teacher has been in a tutoring position in the classroom. For example, students in the process of learning, in view of the key points and difficulties in the knowledge points, through the network services to provide teaching resources for independent thinking and research, to find answers to questions, teachers in this process, through the observation of students' learning situation, students can not solve problems, help them solve their existing doubts, fully highlight the main position of students learning, while teachers can use cloud computing technology to provide a network platform 
to spot check students' homework in order to master the students' learning situation, but also through the platform to answer learning All kinds of questions of students, strengthen the interaction between teachers and students, so as to close the distance between teachers and students, and lay a solid foundation for the realization of efficient teaching quality. In addition, teachers can also use the network platform provided by cloud computing technology to correct homework, check homework and other teaching task ${ }^{[5]}$. Teaching through cloud computing is not only helpful to strengthen students' ability of autonomous learning, to develop good study habits, but also to enhance teachers' work efficiency.

(2) Implementation of individualized teaching

Cloud computing technology assisted teaching helps teachers to carry out personalized teaching, according to the strength of students' learning ability, the degree of mastery of knowledge points and learning interests to set up different learning accounts, according to the level of students' learning ability to assign different learning tasks, and set up different levels of access rights, so that students according to their own learning ability and learning account. For example, in the course of teaching, students $\log$ on to the cloud computing terminal to visit the website, according to their own interests and their own learning needs, log on to the account set by the teacher, Download the teaching resources you need on the network platform provided by cloud computing technology and fail yourself Fully grasp the knowledge points for playback and review, and complete the teacher on the platform assigned homework exercises, deepen their understanding. At the same time, teachers can also provide a network platform through cloud computing technology, according to students' learning needs and abilities, optimize teaching methods, so that teaching methods and students' learning ability match, so as to further help students improve the overall learning level and strengthen the progressive ${ }^{[6]}$ of individualized learning.

\section{(3) Changing Teaching Priorities}

Practice is the most important part of teaching. Strengthening practical teaching is helpful for students to master and use knowledge points flexibly. The traditional teaching mode is more emphasis on the teaching of knowledge theory. The theoretical knowledge is various and complex, which once makes the classroom atmosphere dead. Because of the lack of practical operation, the students' understanding of knowledge points is not comprehensive enough, so they have to memorize by rote. In the course of higher vocational course teaching, it is helpful for teachers to sum up teaching experience, to innovate teaching ideas through teaching resources and data provided by cloud computing technology And then into the teaching goal, enhance the practicality of teaching. Ask students to realize specific operation through mastering theoretical knowledge in the process of learning, and make flexible use of theoretical knowledge through many practical operations. In order to further strengthen the students' ability to solve problems and the skillful use of theoretical knowledge ${ }^{[7]}$. 


\section{IV.Conclusion}

In a word, cloud computing technology, as a new educational model, completely breaks the limitations of traditional teaching mode. Through the network platform created by cloud computing technology, we can provide students with a large number of teaching resources at any time, completely free from the limitation of time and space, and continue to according to their own learning shortcomings. And students can upload and share their learning experience and notes through the network platform provided by cloud computing technology. In addition, cloud-computing-assisted instruction helps students develop their ability to learn independently To realize the educational goal of individualized learning.

\section{References}

[1] Zhao Qian. Research on the Application of Cloud Computing Assisted Teaching to Adapt to the New Development of Informatization — Taking the Teaching of Computer Foundation as an example [J].] Journal of Yang Ling Vocational and Technical College 17(3):62-66.

[2] Qin Lei. Application of Cloud Computing Assisted Teaching in Computer Applications [J].] Course Computer Products and Circulation ,2018(6):235-236.

[3] Wang Jinheng, Wang Yulin. A Study on the Application of Cloud Computing Assisted Teaching in Independent Colleges [J]. Computer Products and Circulation ,2018(12):246-247.

[4] Chen Xiaodan. A Study on the Development and Application of Project Teaching Resources Based on Higher Vocational Cloud Computing Course [J]. Computer knowledge and Technology 15(7):131-132.

[5] Wang Ruina. Application of Collaborative Learning Based on Baihui Cloud Platform in Computer Course Teaching in Higher Vocational Education [J].]; and Journal of Luohe Vocational and Technical College 17(2):78-82.

[6] Fengna. A Study on Computer Teaching Mode of Higher Vocational Education Based on Cloud Computing Technology [J].]; and Digital Communications World, No.158(2):168,2018 189.

[7] Zhang Wendou. Application of Computational Assisted Teaching in College English Course Teaching [J].] Research Education and Teaching Forum ,2018,(45):273-274. 